\title{
Cross-Sectional Analysis of National Dental Residency Match Data
}

\author{
Sivaraman Prakasam, BDS, MSD, PhD; Patrick Brady, DMD; Veeratrishul Allareddy, \\ BDS, MS; Sankeerth Rampa, MBA, MHA; Kyungsup Shin, DMD, PhD; Romesh Nalliah, \\ BDS; Veerasathpurush Allareddy, BDS, PhD
}

Abstract: The Dental Residency Match (DRM) program provides an ethical and unbiased selection process for applicants to postdoctoral dental programs, based on mutual interests of applicants and programs. The aims of this study were to conduct a descriptive analysis of DRM metrics for the years 2008 to 2015 and to test the hypothesis that there was a difference in number of ranks submitted between programs that filled all their offered positions and those that did not. DRM metrics data from years 2008 to 2015 were obtained from the National Matching Service. Trend analyses and panel data assessments were made. Six types of postdoctoral dental programs (GPR, AEGD, oral and maxillofacial surgery, pediatric dentistry, orthodontics, and dental anesthesiology) participate in the DRM program. The results showed that the number of programs participating and number of residency positions offered increased over the study period. The programs that filled all their positions ranked more applicants than the programs that did not fill their positions $(\mathrm{p}<0.05)$. The number of acceptable applicants increased over the study period for all programs except those in dental anesthesiology. These results suggest that participation in DRM is increasing, most programs are able to fill their positions with acceptable applicants, and programs seeking to fill all their positions need to submit a large number of ranks.

\begin{abstract}
Dr. Prakasam is Assistant Professor, Department of Periodontology, Oregon Health \& Science University; Dr. Brady is a graduate student, Department of Orthodontics, University of Iowa; Dr. Veeratrishul Allareddy is Clinical Professor, Department of Oral Pathology, Radiology, Medicine, University of Iowa; Mr. Rampa is a graduate student, College of Public Health, University of Nebraska Medical Center; Dr. Shin is Assistant Professor, Department of Orthodontics, University of Iowa; Dr. Nalliah is Clinical Associate Professor, Department of Cariology, Restorative Sciences, and Endodontics, University of Michigan; and Dr. Veerasathpurush Allareddy is Associate Professor, Department of Orthodontics, University of Iowa. Direct correspondence to Dr. Veerasathpurush Allareddy, Department of Orthodontics, College of Dentistry \& Dental Clinics, University of Iowa, Iowa City, IA 52242; 319-353-5806; Veerasathpurush-Allareddy@uiowa.edu.
\end{abstract}

Keywords: dental education, graduate dental education, advanced dental education, dental internship, school admission criteria, student selection, National Residency Match

Submitted for publication 4/13/16; accepted 8/24/16

$\mathrm{D}$ ental specialty and postdoctoral general dentistry (PGD) education programs are at critical crossroads. Educational debt is high, which may have some impact on new graduates' choosing to enter practice immediately rather than applying to a specialty or PGD program, especially when their debts exceed $\$ 100,000 .{ }^{1}$ The emergence of alternative mechanisms to obtain specialty board certification (not requiring recognition by the American Dental Association [ADA] Council on Dental Education) may also affect enrollment in advanced education. ${ }^{2}$ Total application numbers and first-year enrollment in PGD and specialty programs have seen small increases in recent years. In 2011-12, there were 53,585 applications and 3,372 enrollments in PGD and specialty programs, while for
2015-16, there were 57,212 applications and 3,592 enrollments. ${ }^{3}$

The large pool of applicants and the variety of program choices create significant challenges for applicants, particularly in identifying which program is the best fit for them. From a program's perspective, it becomes a challenge to recruit the right candidates given the competitive nature of the application pool. This fierce competition also engenders some moral and ethical dilemmas. For example, is it ethical to pressure competitive candidates to accept a position through early binding offers, without giving them time to carefully consider their career and life choices? An overarching goal for any program should be to achieve a high level of competitiveness and desirability for potential candidates. An early and 
binding recruitment process reduces the need for a program to be competitive. Such a process may also result in disgruntled residents. ${ }^{4}$

Most advanced education programs have addressed this challenge by adopting the mechanism of Dental Residency Match (DRM). The DRM emerged from the national residency match program, developed in 1952 to assist medical programs in matching with potential medical residents. The services of this program were first extended to postdoctoral dental programs in 1985 in the form of the DRM, also referred to as "Match." The DRM process was initially developed and organized by the oral and maxillofacial surgery residency programs. This process was then expanded and is currently being utilized by other programs including Advanced Education in General Dentistry (AEGD) and General Practice Residency (GPR) programs and residency programs in orthodontics, pediatric dentistry (PED), and dental anesthesiology (ANES). ${ }^{5,6}$

The Match process involves students' and graduates' applying to their desired advanced education program, either directly or through the American Dental Education Association (ADEA)'s Postdoctoral Application Support Service (PASS). The programs then select the applicants they wish to interview. Based on the interview, the applicants and the programs submit their respective rankings to the National Matching Service (NMS). The NMS uses a "best fit" optimization algorithm to place individuals into positions, based entirely on the preferences that they state in their rank order lists. Neither the applicant nor the program is provided with rankings of other applicants/programs and receive only information related to their own candidacy/program. ${ }^{4,6}$ Thus, if strictly adhered to and uniformly adopted, the DRM process provides an ethical and unbiased selection process, based entirely on the mutual interests of the applicant and the program. ${ }^{4}$ This process may result in increased satisfaction of both the matched applicants and the programs that they match into. ${ }^{7,8}$

Despite the advantages of the Match process, several programs in various PGD and specialty groups, as well as other ADA-recognized specialties, do not participate in the DRM. For example, the specialties of periodontics and endodontics do not participate in it. ${ }^{9,10}$ A previous study examined factors that contributed to one specialty residency program's decision to participate or not participate in the DRM. ${ }^{4}$ The aims of this study were to conduct a descriptive analysis of DRM metrics for the years
2008 to 2015 and to test the hypothesis that there was a difference in number of ranks submitted between programs that filled all offered positions and those that did not fill all offered positions.

\section{Methods}

Since the study used publicly available data, Institutional Review Board exempt status was granted by the Office of Human Subjects Protection at the University of Iowa (IRB \# 201508768). For the study, we used summary statistics from the National Residency Matching Program (NRMP) website (www. natmatch.com/dentres/aboutstats.html) for the years 2008 to 2015.

Data were collected from the NRMP website (www.natmatch.com/dentres/stats/2016progstats. html) for the following variables: programs participating in Match; positions offered in Match; average number of rankings submitted by programs (programs filling all positions and programs with unfilled positions); number of applicants ranked by at least one program ("acceptable applicants"); ratio of acceptable applicants to position; percentage of programs/positions filled in Match; and, for three ADA-recognized specialties (oral and maxillofacial surgery, pediatric dentistry, and orthodontics), distribution of ratio of the least preferred matched rank to the number of positions filled (this quantifies how far down the list a program went to fill its positions).

Simple descriptive statistics were used to summarize the data. Trend analyses and panel data assessments were performed to determine longitudinal changes in the metrics. Plots were used to present the data in figures. The average numbers of ranks submitted per position were compared between programs that filled all offered positions and those that did not fill all offered positions by using Wilcoxon signed-rank test within each year. In this approach, the unit of analysis was the individual year. Within each year, the total number of ranks submitted by programs that completely filled their positions was also compared with the number of ranks submitted by programs that did not fill their positions. Since a within-year comparison was made, the Wilcoxon signed-rank test was used. Separate analyses were conducted for each program. All statistical tests of associations were two-sided, and a p-value of $<0.05$ was deemed to be statistically significant. Statistical analyses were conducted using SPSS Version 23.0 (IBM Corp., New York, NY, USA). 


\section{Results}

During the study period (2008 to 2015), six types of residency programs (GPR, AEGD, oral and maxillofacial surgery, pediatric dentistry, orthodontics, and dental anesthesiology) participated in the DRM. Dental anesthesiology started participating in the year 2011. Over the study period, there was an increase in number of programs participating in the DRM. In 2008, a total of 408 programs (across five types of residencies) participated in the DRM, while in 2015 a total of 473 programs (across six types of residencies) participated. The total number of residency positions offered in the DRM increased from 1,716 (year 2008) to 2,065 (year 2015). GPR programs had the most number of positions offered through DRM annually, followed by pediatric dentistry, AEGD, orthodontics, oral and maxillofacial surgery, and dental anesthesiology.

The mean and median numbers of ranks submitted by programs that filled all positions and those that did not are shown in Table 1. When Wilcoxon signed-rank tests were used to compare differences in average number of ranks submitted per position offered in each year between programs that filled all their positions and those that did not, it was evident that programs able to fill all their positions ranked more applicants than programs that did not. These differences were statistically significant for all types of residencies (GPR $p=0.01$; AEGD $p=0.01$; oral and maxillofacial surgery $p=0.01$; pediatric dentistry $\mathrm{p}=0.01$; orthodontics $\mathrm{p}=0.01$; and dental anesthesiology $\mathrm{p}=0.04)$.

The ratios of acceptable applicants per positions filled for all programs are shown in Figure 1. Overall, the ratio of acceptable applicants stayed relatively stable and ranged from a low of 0.8 (dental anesthesiology for 2015) to a high of 1.6 (orthodontics in 2009, 2014, and 2015). For all these types of residencies except dental anesthesiology, there was trend towards increase in the number of acceptable applicants over the study period. This trend was most pronounced for GPR programs.

Across all years, the three specialty residencies (oral and maxillofacial surgery, pediatric dentistry, and orthodontics) did extremely well in filling positions in the DRM. Overall, more than $90 \%$ of all programs and $95 \%$ of all positions in these three specialties were filled in the DRM (Figure 2 and Figure 3). AEGD programs fared the worst in terms of filling their positions followed by GPR and dental anesthesiology programs.

The overall average ratio of the least preferred matched rank to the number of positions filled was computed for the three specialties (oral and maxillofacial surgery, pediatric dentistry, and orthodontics; Figure 4, Figure 5, and Figure 6). Close to $35 \%$ of oral and maxillofacial surgery programs, $30 \%$ of pediatric dentistry programs, and $30 \%$ of orthodontics programs had a ratio of 1 to $<1.5$ for ratios of least preferred match rank/positions filled.

Table 1. Average number of ranks offered per position for each type of postdoctoral program

\begin{tabular}{|c|c|c|c|c|c|c|}
\hline Program & Years & $\begin{array}{l}\text { Programs Filled } \\
\text { All Positions } \\
\text { in Match }\end{array}$ & $\begin{array}{l}\text { Numbe } \\
\text { Mean }\end{array}$ & $\begin{array}{c}\text { anks All Ye } \\
\text { Median }\end{array}$ & $\begin{array}{l}\text { Combined } \\
\text { Std. Dev. }\end{array}$ & $\mathrm{p}$-value \\
\hline GPR & 2008-15 & $\begin{array}{l}\text { Yes } \\
\text { No }\end{array}$ & $\begin{array}{l}4.11 \\
2.34\end{array}$ & $\begin{array}{l}4.05 \\
2.30\end{array}$ & $\begin{array}{l}0.24 \\
0.27\end{array}$ & 0.01 \\
\hline AEGD & 2008-15 & $\begin{array}{l}\text { Yes } \\
\text { No }\end{array}$ & $\begin{array}{l}3.25 \\
1.62\end{array}$ & $\begin{array}{l}3.35 \\
1.70\end{array}$ & $\begin{array}{l}0.22 \\
0.33\end{array}$ & 0.01 \\
\hline Oral and maxillofacial surgery & 2008-15 & $\begin{array}{l}\text { Yes } \\
\text { No }\end{array}$ & $\begin{array}{l}7.10 \\
4.31\end{array}$ & $\begin{array}{l}7.10 \\
4.30\end{array}$ & $\begin{array}{l}0.23 \\
1.00\end{array}$ & 0.01 \\
\hline Pediatric dentistry & 2008-15 & $\begin{array}{l}\text { Yes } \\
\text { No }\end{array}$ & $\begin{array}{l}4.56 \\
2.73\end{array}$ & $\begin{array}{l}4.55 \\
2.50\end{array}$ & $\begin{array}{l}0.17 \\
0.42\end{array}$ & 0.01 \\
\hline Orthodontics & 2008-15 & $\begin{array}{l}\text { Yes } \\
\text { No }\end{array}$ & $\begin{array}{l}4.96 \\
2.96\end{array}$ & $\begin{array}{l}5.00 \\
2.85\end{array}$ & $\begin{array}{l}0.12 \\
1.04\end{array}$ & 0.01 \\
\hline Dental anesthesiology & 2011-15 & $\begin{array}{l}\text { Yes } \\
\text { No }\end{array}$ & $\begin{array}{l}3.66 \\
1.60\end{array}$ & $\begin{array}{l}3.80 \\
1.40\end{array}$ & $\begin{array}{l}0.43 \\
0.62\end{array}$ & 0.04 \\
\hline
\end{tabular}

Note: The p-values were determined by the Wilcoxon signed-rank test. 


\section{Discussion}

Six types of advanced education programs in dentistry participate in the DRM program. ${ }^{6}$ Among the ADA-recognized specialties, periodontics, endodontics, prosthodontics, oral and maxillofacial pathology, oral and maxillofacial radiology, and dental public health programs do not participate in the DRM. A comparison of the number of applicants to enrollments showed that, on average, the programs that did not participate in the DRM process typically had a lower number of applicants. ${ }^{3}$ This difference perhaps reflects the added difficulty applicants face in navigating the application systems of individual programs and dealing with the logistics of applying to multiple programs. For example, a survey of endodontic residents found that "respondents were not overwhelmingly satisfied with the application/ interview/selection process and 39\% indicated they would have preferred a Match process." "11 In that study, the authors argued for an improved resident selection process. A previous study by Bell et al. found that endodontic directors were supportive of at least a uniform acceptance date for all programs. ${ }^{10}$

This situation mirrors what medical residency programs went through in the early 1900 s. ${ }^{12,13}$ Hospitals were filling positions with inexperienced medical students based on very little data about the qualities of the applicants, and students were accepting offers without adequate information about their options. These problems eventually led to widespread use of so-called "exploding offers" (offers often valid for only 12 hours). In some dental specialties, even in admission cycles of the past few years, we have observed that such exploding offers are not uncommon. Consequent to that, non-Match-participating dental specialties have tried to establish what some called a "gentlemen's agreement" in which programs agreed to communicate position offers to applicants only on or after a previously agreed set day. ${ }^{11}$ Medical programs made a similar attempt in the late 1940s that was said to have failed miserably. ${ }^{13}$ Adherence to this kind of courtesy agreement by dental residency programs seems limited at best.

In this context, we explored the metrics of DRM programs between 2008 and 2015. Match metrics have been reported more frequently by medical than dental specialties and are usually restricted to a particular type of specialty (primary care, family medicine, etc.). ${ }^{14,15}$ Considering the relatively limited number of types of dental residencies participating in the DRM, we were unable to explore metrics for the dental profession as a whole. Similar to previous reports in the medical literature, through this analysis we hoped to provide some lessons for programs that

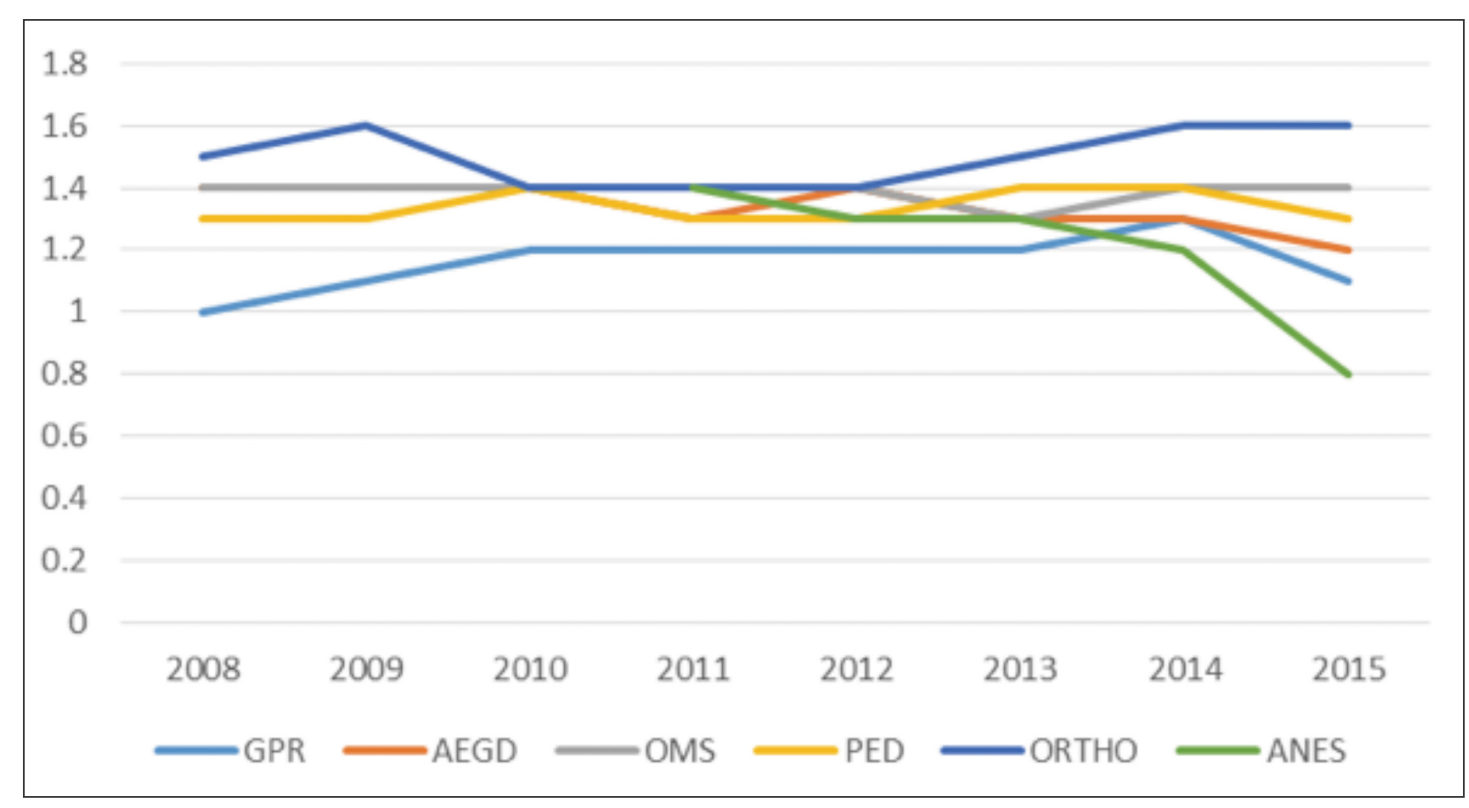

Figure 1. Ratio of acceptable applicants per position filled, 2008-15 
participate in the Match process to enhance successful outcomes. An additional goal was to report on Match outcomes that may or may not encourage nonparticipants to reassess their decision to not participate.
The number of programs participating increased over the years in the study, largely due to increased number of AEGD programs participating in the Match process. The number of positions offered in the Match increased as well, also largely

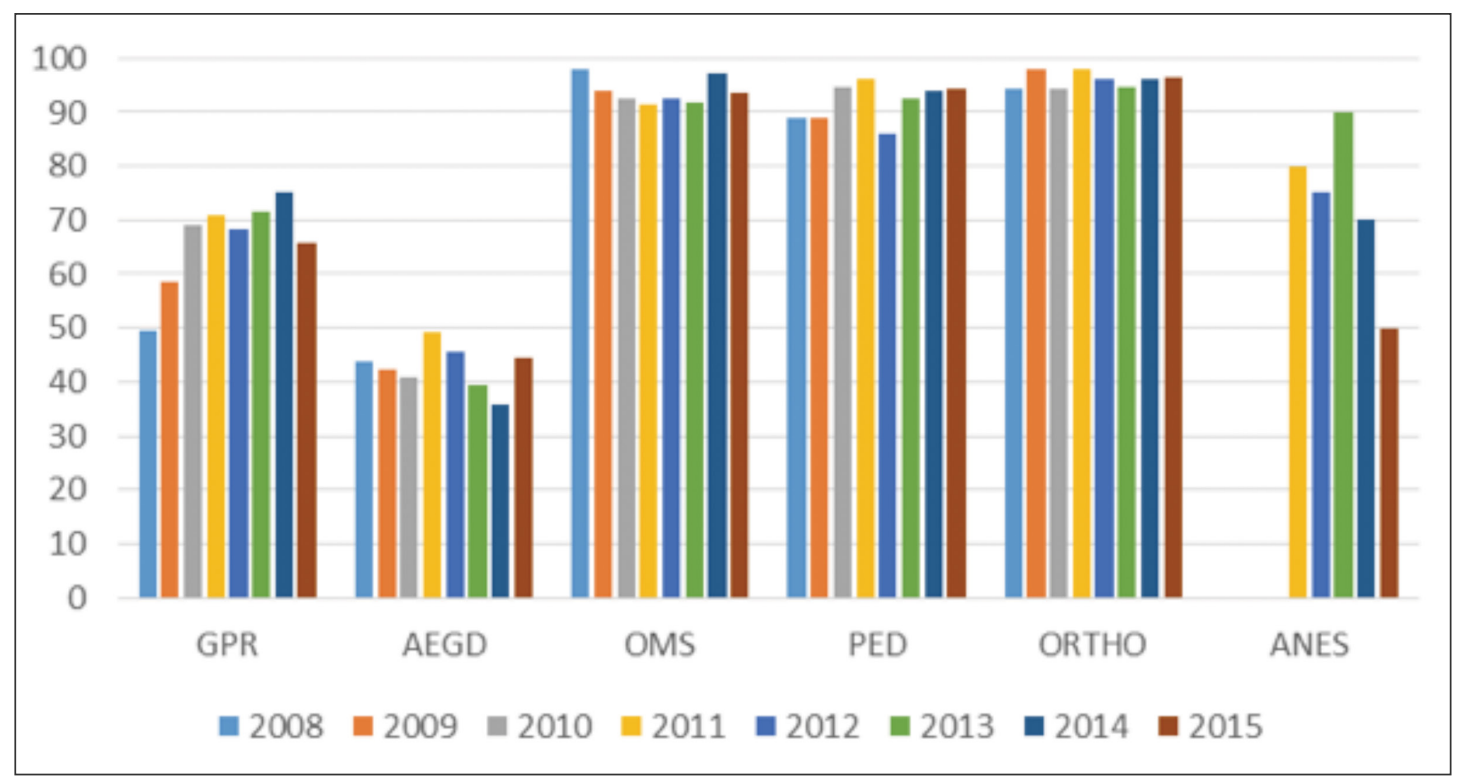

Figure 2. Percentage of programs filled in DRM, 2008-15

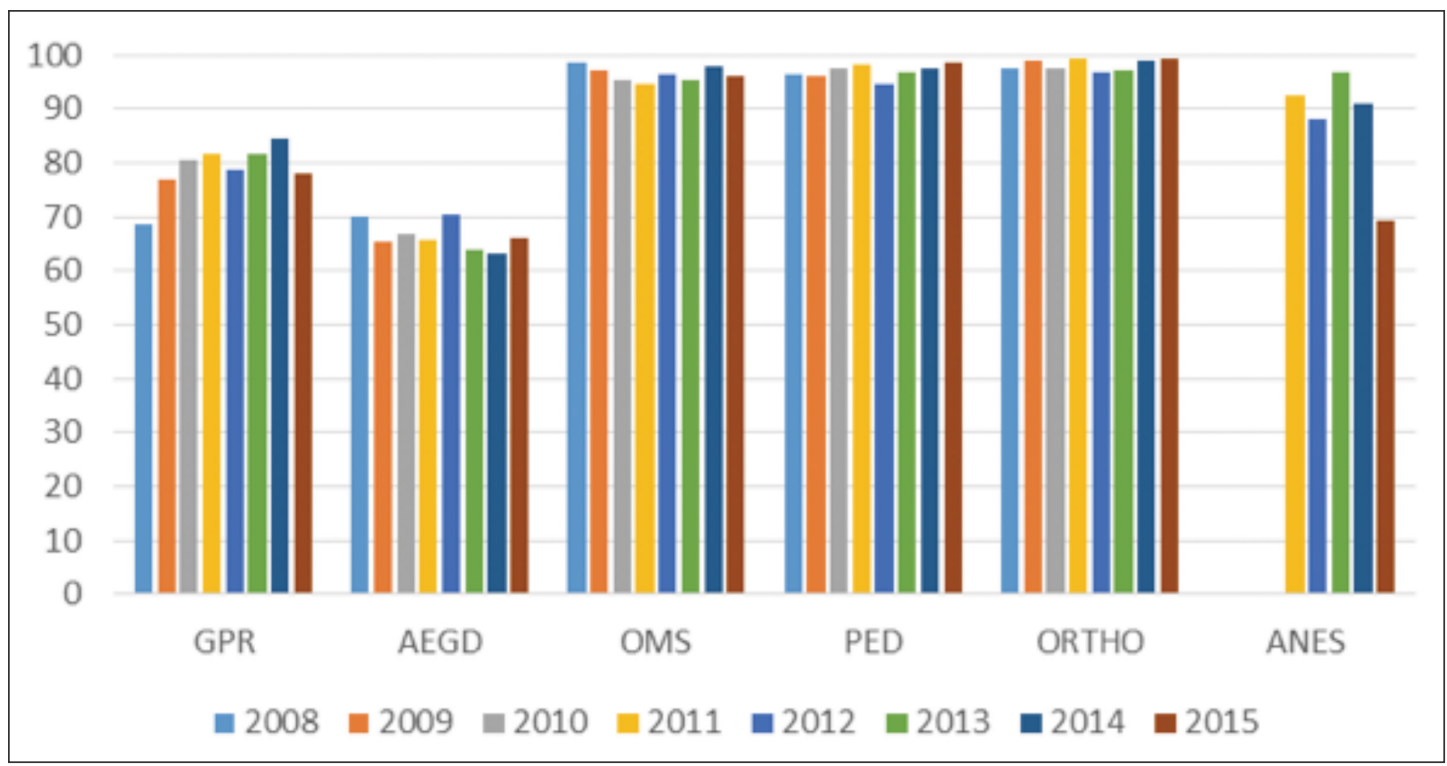

Figure 3. Percentage of positions filled in DRM, 2008-15 


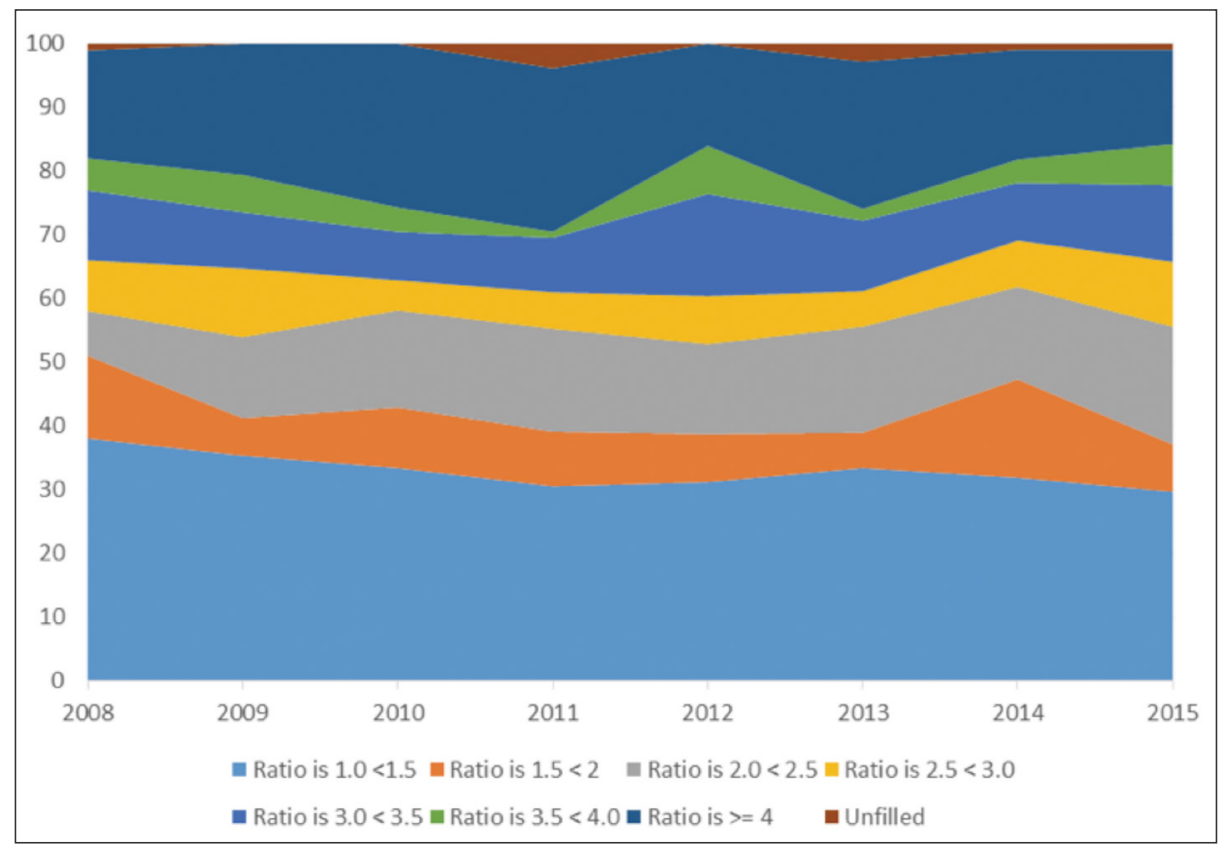

Figure 4. Oral and maxillofacial surgery programs: percentages of ratios of least preferred match rank/positions filled, 2008-15

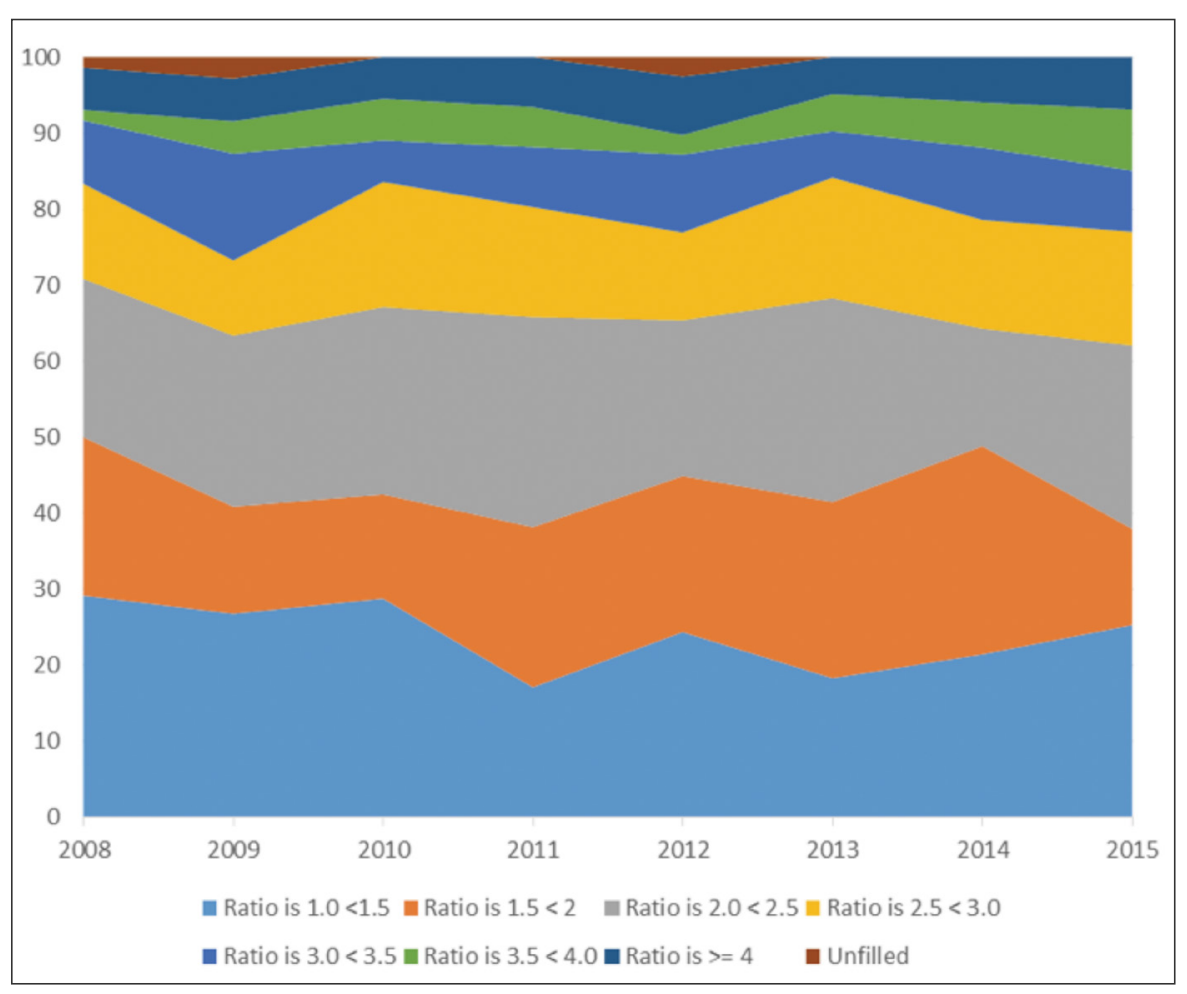

Figure 5. Pediatric dentistry programs: percentages of ratios of least preferred match rank/positions filled, 2008-15 


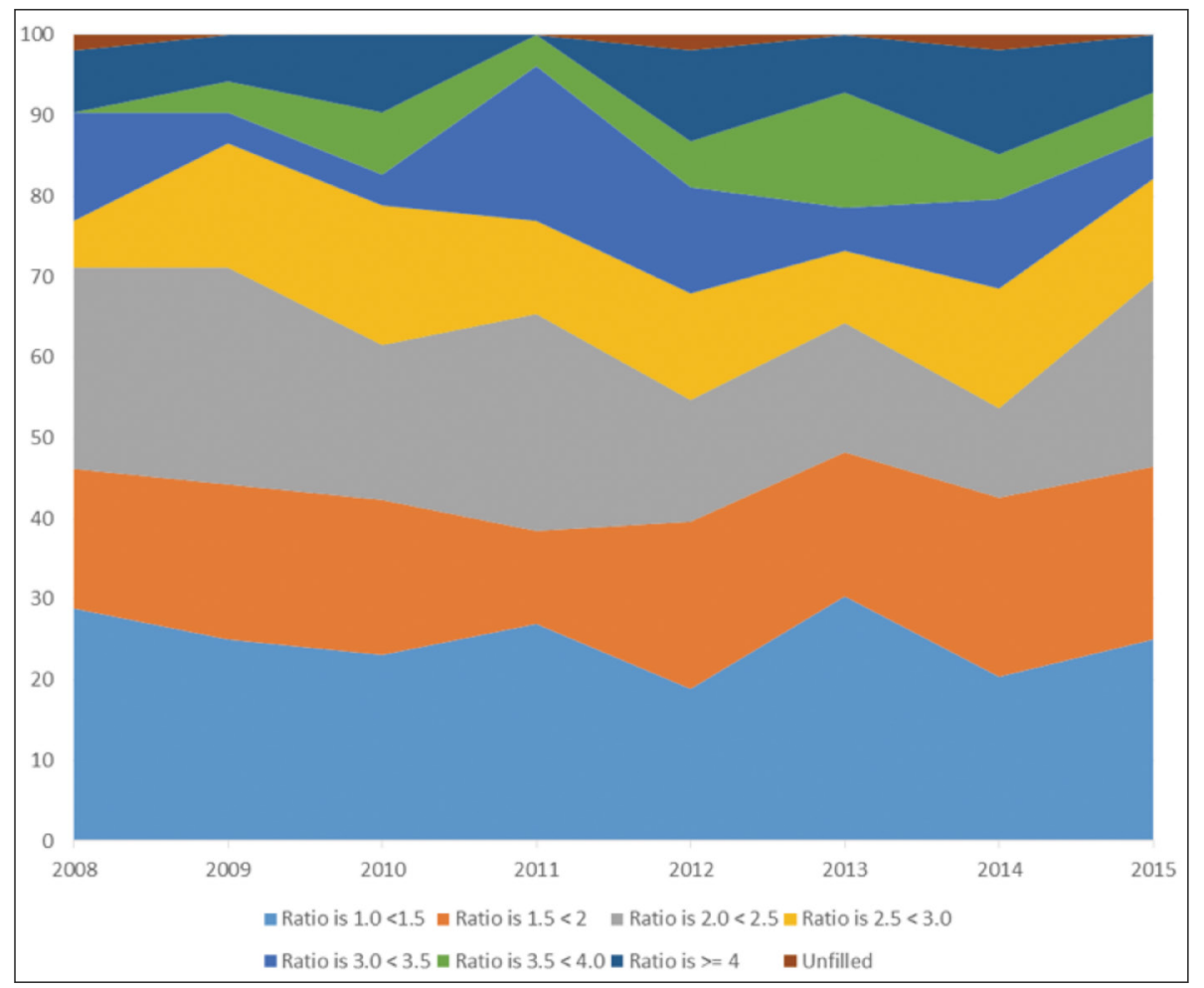

Figure 6. Orthodontics programs: percentages of ratios of least preferred match rank/positions filled, 2008-15

due to an increase in number of AEGD and GPR positions. Our study found that programs that filled all their positions submitted a larger number of ranks per position than programs that did not fill all their positions. This pattern was evident for all the types of programs in the study. This finding suggests that, if filling all positions is one of the programs' objectives, they need to submit more ranks. Increasing the number of ranks submitted may result in better matching and filling their positions. However, it does not necessarily mean that the programs can fill positions with the same quality of applicants unless there are more applicants to the program. This is an important issue that warrants further exploration. The lack of data on total number of applications to a program precluded us from examining that factor, which is an inherent limitation of the study.

It was particularly encouraging to see an increase in the number of acceptable applicants, especially among GPR programs. The ratio of acceptable applicants per position also stayed relatively stable. This finding likely reflects the interest among recently graduated dentists to gain experiences in more advanced dental procedures. It could also be a reflection of some state licensing boards' move to licensing through advanced training in lieu of licensing exams. Alternatively, it could be due to the reluctance of new graduates to enter the job market due to depressed economic conditions during the time period of this study. ${ }^{16,17}$

Our results showed that anesthesiology programs had a decrease in the number of acceptable applicants and the lowest number of applicants among the programs participating in Match. Anesthesiology programs also fared worst among all the Match programs in filling positions. Dental schools may need to recognize this and help aspiring anesthesiologists prepare a career path toward residency programs by providing formative and summative assessments in dental anesthesiology concepts and utilizing robust feedback mechanisms to increase interest in the field. For example, dental schools could provide enhanced rotational opportunities in anesthesiology for students that emphasize one-on-one contact time with trained dental anesthesiologists. Such specialist contact has been found to have some success in 
increasing student interest in the specialty of oral and maxillofacial surgery. ${ }^{18}$ Another mechanism is the creation of a predoctoral study club for dental anesthesiology. Given that predoctoral students receive limited exposure to dental anesthesiology, such focused programs could help students become more aware of the skills and talent they have for that specialty. This awareness has been found to be one of the most important reasons students choose to pursue a particular specialty. ${ }^{19}$ An alternative explanation for the lower number of acceptable applicants and reduction in the number of filled positions in dental anesthesiology could be due to the fact that they are relatively new entrants to the DRM process.

We found that oral and maxillofacial surgery, pediatric dentistry, and orthodontics programs were able to fill their residency positions and they were able to do that with a greater cohort of acceptable applicants. Their success rates probably reflect the inherent attractions of those specialties..$^{16,20,21}$ AEGD programs fared the worst among the cohorts. That finding could be explained as reflection of the increased number of positions, resulting in a surplus situation. Alternatively, increasing student loan burden may be preventing students from enrolling in PGD programs if the economic advantage of quickly paying off loans is not as apparent as for other advanced programs. ${ }^{1,16}$

\section{Conclusion}

Through this study, we identified important trends that may be useful for programs and residency applicants, so that they can become successful in identifying mutually beneficial matches through the DRM process. Participation in DRM is increasing, and we hope the increased adoption will encourage more programs to become part of this process. The Match offers an ethical and unbiased mechanism, which simplifies and reduces the burden on students intending to pursue advanced training. If filling positions is an important objective for advanced dental education programs, it is safe to conclude that programs need to submit greater number of ranks. Dental schools also need to note the reduction in acceptable applicants to anesthesiology programs. Consequent to this, exposure to advanced procedures as well as exposure to specialty role models must be encouraged. In addition, structured programs to encourage future residents should be offered in dental schools.

\section{Disclosure}

The authors declared no conflicts of interest associated with the conduct of the study or publication of its findings.

\section{REFERENCES}

1. Nashleanas BM, McKernan SC, Kuthy RA, Qian F. Career influences among final year dental students who plan to enter private practice. BMC Oral Health 2014;14(1):18.

2. Texas court ruling allows non-ADA-recognized specialty dentists to advertise as "specialists." ADA News. At: www.ada.org/en/publications/ada-news/2016-archive/ january/texas-court-ruling-allows-non-ada-recognizedspecialty-dentists-to-advertise-as-specialists. Accessed 4 Apr. 2016.

3. American Dental Education Association. ADEA snapshot of dental education, 2015-16. At: www.adea.org/snapshot/. Accessed 4 Apr. 2016.

4. Allareddy V, Srinivasan S, Southard TE. Match or nonmatch: at the crossroads. Am J Orthod Dentofacial Orthop 2015;148(5):748-54.

5. da Fonseca MA, Pollock M, Majewski R, et al. Factors influencing candidates' choice of a pediatric dental residency program. J Dent Educ 2007;71(9):1194-202.

6. National Dental Matching Services, Inc. Postdoctoral dental matching program. At: www.natmatch.com/dentres/. Accessed 4 Apr. 2016.

7. Laskin DM, Lesny RJ, Best AM. The residents' viewpoint of the matching process, factors influencing their program selection, and satisfaction with the results. J Oral Maxillofac Surg 2003;61(2):228-33.

8. Spina AM, Smith TA, Marciani RD, Marshall EO. A survey of resident selection procedures in oral and maxillofacial surgery. J Oral Maxillofac Surg 2000;58(6):660-6.

9. Khan S, Carmosino AJ, Yuan JCC, et al. Postdoctoral periodontal program directors' perspectives on resident selection. J Periodontol 2015;86(2):177-84.

10. Bell LT, Sukotjo C, Yuan JCC, Johnson BR. Applicant selection procedures in endodontic specialty programs in the United States: program directors' perspective. J Endod 2014;40(6):797-804.

11. Woodmansey KF, He J, Glickman GN. Residents' perceptions of the graduate endodontic application selection process and match. J Endod 2015;41(8):1248-52.

12. Nagarkar PA, Janis JE. Fixing the "match": how to play the game. J Grad Med Educ 2012;4(2):142-7.

13. Sapareto S, Zhu XR, Orton CG. Point/counterpoint: medical physics residents should be placed using a matching program. Med Phys 2014;41(6):060601.

14. Flannery MT. The 2014 United States National Residency Match Program data for primary care programs: a review. Eur J Intern Med 2015;26(1):6-8.

15. Kozakowski S, Crosley P, Bentley A. Results of the 2014 national resident matching program: family medicine. Fam Med 2014;46(9):701-6.

16. Dhima M, Petropoulos V. Dental students' perceptions of dental specialties and factors influencing specialty and career choices. J Dent Educ 2012;76(5):562-73. 
17. Vujicic M, Wall T, Nasseh K, Munson B. Dentist income levels slow to recover. Health Policy Resource Center. Chicago: American Dental Association, 2013.

18. Marciani RD, Smith TA, Heaton LJ. Applicants' opinions about the selection process for oral and maxillofacial surgery programs. J Oral Maxillofac Surg 2003;61(5):608-14.

19. Saeed S, Jimenez M, Howell H, et al. Which factors influence students' selection of advanced graduate programs? One institution's experience. J Dent Educ 2008;72(6): 688-97.
20. Ricker K, Mihas P, Lee JY, et al. Educators' and applicants' views of the postdoctoral pediatric dentistry admission process: a qualitative study. J Dent Educ 2015;79(11):1272-8.

21. Shin JH, Kinnunen TH, Zarchy M, et al. Factors influencing dental students' specialty choice: a survey of ten graduating classes at one institution. J Dent Educ 2015;79(4):369-77. 